\title{
Optimization of the Production Process of Vibrocasted Refractory Products
}

\author{
Martin $\mathrm{Kyncl}^{1, *}$, Jiri Kyncl ${ }^{1}$, and Michal Slany ${ }^{1}$ \\ ${ }^{1}$ Czech Technical University in Prague, Faculty of Mechanical Engineering, Department of \\ Technology of Machining, Process Planning and Metrology, Technická 4, 16607 Praha 6, Czech \\ Republic
}

\begin{abstract}
This paper deals with the optimization of the production process of vibrocasted refractory products. The main goal is to make efficient and automate the production of moulds for refractory blocks. A theoretical research was followed by an expert analysis of the current state of the manufacturing process at an industrial partner. The next step was to analyze complete portfolio of refractory vibrocasted products, which results in choosing a representative sample whose dimensions most correspond to majority of the moulds produced. Subsequently, a design was done, to make the production process more effective with respect to time, technology and construction aspects, focusing on increasing productivity, reducing human labour and increasing production modernization. In the end, the design options were evaluated in terms of time and cost, and the ideal process of the manufacturing production was recommended with respect to the latest technology. It includes a solution for material composition and optimized design of moulds for vibrocasted refractory materials to increase production efficiency moulds and cost reduction while maintaining mould accuracy and quality. These products are subject to high demands in terms of material quality and precision, and at the same time costly to produce due to manual manufacturing.
\end{abstract}

\section{Current State of Production}

At present, mould production in the company does not have a solid workflow. Technological procedures are not processed and everything is based only on the experience and skills of the production workers. Conventional woodworking machines are used in production, making complex products difficult to produce and not with the necessary shape or geometric accuracy. Also, moulds often cannot be dimensionally checked. The remaining dimensions can only be measured after casting the brick and the subsequent mould modification is much more complex.

Production and systematization documentation is also not in the best condition. Based on customer demand, the manufacturing division contacts the service division with the task of setting the price and deadline for production. In the event of a positive customer

*Corresponding author: martin.kyncl@fs.cvut.cz 
response, the service division will begin processing the necessary documentation in the form of $3 \mathrm{D}$ models and then drawing the specified brick.

\subsection{Continuous Production Time of Brick}

The current structure of bricks production is partly described by the evaluation of the time demands of individual operations in the Gantt diagram (Fig. 1). However, this diagram is too general and difficult to reflect on the complexity of the various bricks. For simpler types of bricks, production is carried out in larger series, so the production of the bricks themselves can take more time than mould production. For particularly large weight piece bricks, mould design and manufacture becomes the dominant part of the process.

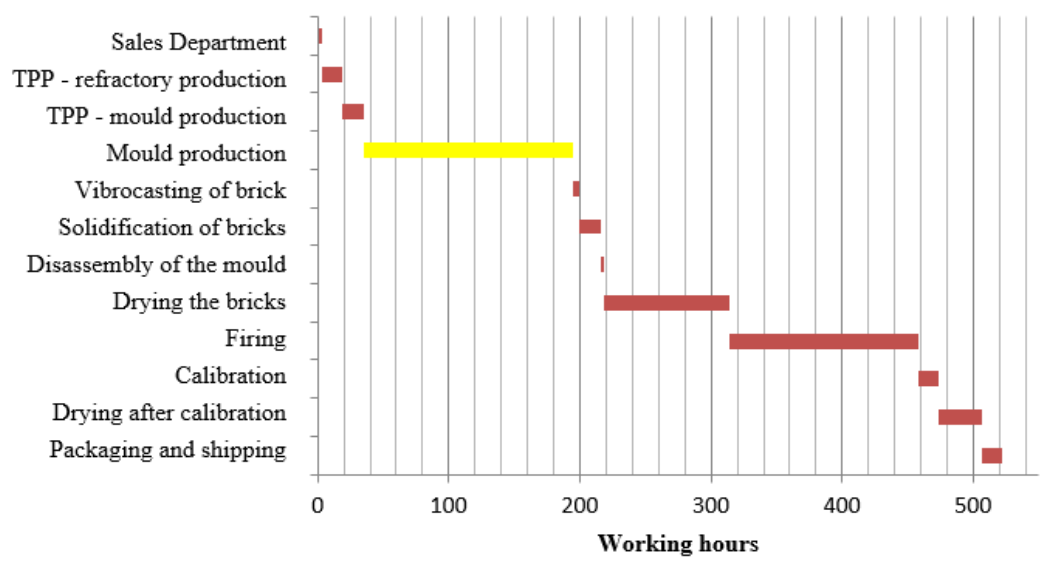

Fig. 1. Gantt Diagram of Production of Brick

The current state of production described above is no longer usable for the increasing number of orders. Production documentation of moulds is available only in hand-drawn form. Thus, there is no uniform methodology for how to design forms, and each form is also unique without any unification of at least external dimensions whose pre-production could save time of preparation. A significant proportion of manual production also extends production times and reduces repeatability. It also puts more emphasis on measurements that are difficult with current equipment.

\subsection{Requirements for New Production Technology}

The aforementioned shortcomings and reserves in possible procedures set out the requirements that should be used to increase work efficiency, reduce time requirements and ideally also reduce current high material and human labour costs.

It can be seen on the Gantt Diagram of Production Time-consuming (Fig. 1) that the mould making process takes up more than a third of the production time from the entire brick manufacturing process. The quality of the surface of the bricks, although not very important from the point of view of function. The introduction of methodologies for mould design could reduce the burden on designers and technology managers. Also, the introduction of common, standardized elements, such as the outer mould frame, would accelerate both design and manufacture. More emphasis should be placed on preserving production documentation together with the use of new capacities in the form of a CNC milling machine. Current moulds are stored for several years at the company's premises for repeated production. The possibility of using inexpensive and quick-to-manufacture 
moulds, albeit with a limited lifespan, which could be produced quickly if necessary, would reduce the space required to store them and thus remove part of the space costs.

All of the above requirements can be seen as an effort to reduce costs and shorten the manufacturing process. By shortening the production process, it is mainly meant to reduce labour and any additional time costs so as to achieve the lowest possible cost of production and maximum efficiency (see Fig. 2).

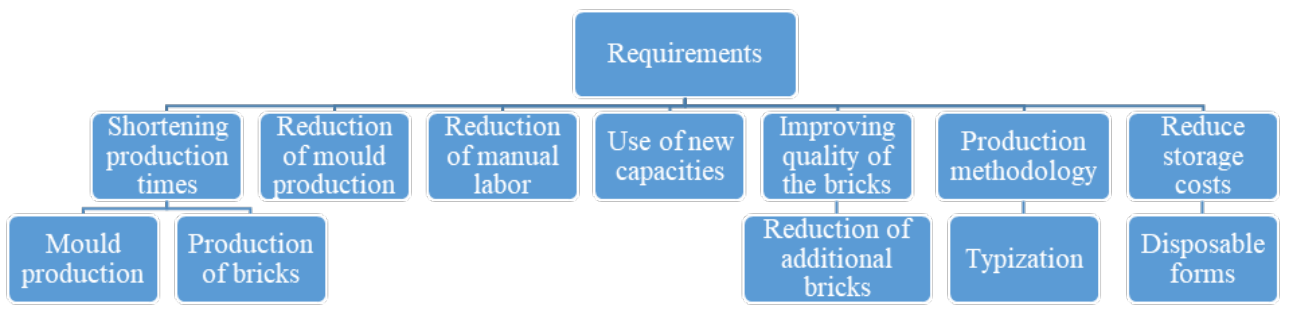

Fig. 2. Requirements for New Production Technology Diagram

\section{Choosing a Representative}

Prior to the design of the production technology, an analysis was made of the composition of the orders already produced by the company in order to identify the common features of the products and, of course, gain insight into the bricks and moulds themselves. Between 2013 and 2016, a total of 428 types of bricks were produced, of which 570 moulds were manufactured for the needs of pressing 10,897 pieces of bricks. Pareto (ABC) analysis was used to evaluate the spectrum of production. To the individual types of fittings subjected to analysis, characteristics were assigned according to the drawing: height, width, length, weight, use of the core, special external shapes and internal shapes that influence the construction of the mould. Also, material costs and labour costs for individual types of bricks have also been written.

On the basis of evaluation of individual characteristics it is possible to evaluate the value of the characteristic which corresponds to the effort to find as many forms as possible equal to the smallest interval of values. However, this assessment is not sufficient because the characteristics are related. Therefore, based on the characteristic values (Table 1), bricks not conforming to the characteristics were sorted again and gradually.

Table 1. Evaluation of Characteristics - Independent

\begin{tabular}{|c|c|c|c|c|c|}
\hline Factor & $\begin{array}{c}\text { Number } \\
\text { of } \\
\text { Moulds }\end{array}$ & $\begin{array}{c}\text { Total } \\
\text { number of } \\
\text { Moulds }\end{array}$ & $\begin{array}{c}\text { Characteristic } \\
\text { value }\end{array}$ & $\begin{array}{c}\text { Moulds } \\
\text { percentage }\end{array}$ & $\begin{array}{l}\text { Dimension } \\
\text { percentage }\end{array}$ \\
\hline Height & 553 & \multirow{7}{*}{570} & $400 \mathrm{~mm}$ & 97 & 40 \\
\hline Width & 457 & & $500 \mathrm{~mm}$ & 80 & 30 \\
\hline Depth & 423 & & $500 \mathrm{~mm}$ & 74 & 29 \\
\hline Weight & 416 & & $50 \mathrm{~kg}$ & 97 & 4 \\
\hline Core & 390 & & no & 70 & \\
\hline External shape & 309 & & no & 65 & \\
\hline Internal shape & 258 & & no & 47 & \\
\hline
\end{tabular}


According to the characteristic values found in the previous section, a selection analysis was carried out, which gradually eliminates unsatisfactory bricks. The aim was to identify a common representative applicable to the design of a common production technology.

\section{Design Concept of New Mould}

The present design has a high weight and associated handling, assembly and manufacturing effort, as well as handling demands for casting refractories due to flow into the mould cavities. The current design of vibrocasted material moulds does not allow standardization and eventual automation of production. The current design solution does not allow the use of new lightweight perspective materials. [1, 2]

Development and optimization activities can be divided into two stages:

1. Development of the material composition of the new type of mould (mould lining)

2. Development of the design of a new type of mould (mould lining + mould frame)

\subsection{Material used for Inner Mould's Segments}

At present, natural wood and natural wood-based materials (MDF) are used as structural material for moulds for casting refractory vibrocasted materials (see in Fig. 3 on the left). The critical point of the manufacturing process of the refractory vibrocasted materials is the solidification of the vibrocasted brick in the mould cavity.

The main aim of the design was to ensure shrinkage of the brick without its destruction and at the same time to make the mould production more efficient. After extensive research of suitable solutions, a suitable group of materials for internal moulding was selected from foam materials, namely polyurethane (PUR) foam and polystyrene. However, without external support, these materials do not have sufficient strength to maintain the outer shape when solidifying. Therefore, when using these materials, it is necessary to select the appropriate support - that is, the outer mould frame. [3, 4]

The essence of the material solution is that the mould is made of three construction materials. The first type of material is polyurethane (PUR) foam. This material ensures a high quality of the surface of the final products, e.g. vibrocasted bricks. The second type of material is hardened polystyrene, which will be applied to the moulds and will enable productive production through the use of modern $\mathrm{CNC}$ technology. Material testing has been extensively tested for the purpose of defining a suitable starting material for machining, defining suitable cutting conditions, and selecting machining tools to achieve high surface quality. The third type of material is soft polystyrene.

\subsection{Design of Outer Mould's Segments}

Based on the concept, other frame variants have been developed, including the prototype frame shown in Fig. 3 (on the right). The main difference from the concept is the use of other compensating members - in the case of a prototype, they are pneumatic bellows. These are not located on movable members but on fixed parts of the frames. This makes handling the moving frame parts easier. To cast a moulded brick, it is necessary to insert the inner moulding of the foam mould into the outer frame space (blue parts in Fig. 3 on the right). When the mould is inserted and settled, the pneumatic bellows are blown up to operating pressure.

These will generate sufficient pressure across the distribution plate to fit all the mould parts accurately. Thereafter, the vibrocasted mixture may be poured. During the casting process, the entire frame is placed on a vibrating plate. After the casting is completed, a 
solidification stage occurs in which the shrinkage of the materials is compensated by both the foam material and the pneumatic members.
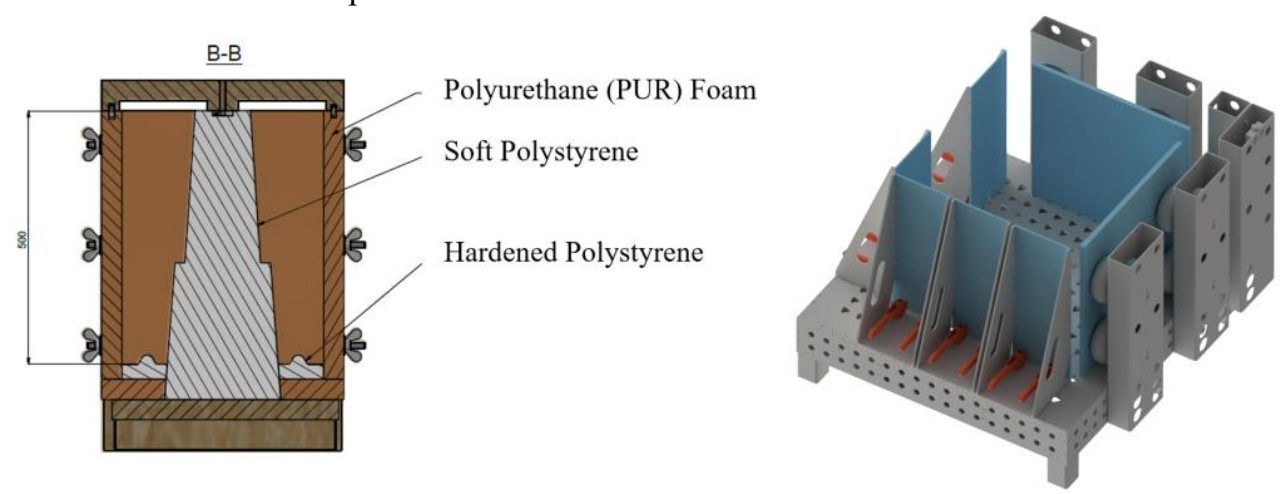

Fig. 3. Design of Inner Mould's Segments (left) and Prototype of Outer Frame (right)

This prototype frame is designed for shaped bricks with a maximum size of $500 \times 500$ $\mathrm{mm}$. Thus, it is possible to place a mould of foam materials with a maximum dimension of $600 \times 600 \mathrm{~mm}$. Thanks to the movable members with a sufficient step and thanks to the pneumatic bellows with sufficient long run, it is possible to cast any bricks into the maximum dimension. The shape of the outer frame was also designed for effortless handling (pallet truck space and the ability to mount on a crane) and the ability to fit it into an automated production line.

\subsection{Optimization Criteria}

The loading force acting on the mould and the frame is given by the hydrostatic force and the net weight of the mixture into the mould. The specific gravity $\rho$ of the different types of mixtures is not the same and ranges from about 2500 to $3500 \mathrm{~kg} / \mathrm{m} 3$. For design purposes, the highest density was calculated.

Hydrostatic pressure

$$
p=h \cdot \rho \cdot g=0,4 \mathrm{~m} \cdot 3500 \mathrm{~kg} / \mathrm{m}^{3} \cdot 9,81 \mathrm{~m} / \mathrm{s}^{2}=13734 \mathrm{~Pa}
$$

The force acting on the wall

$$
F=p \cdot h / 2 \cdot l=13734 \cdot 0,4 / 2 \cdot 0,5=1373,4 N
$$

The hydrostatic force acting on the wall is continuously distributed from the level where the force is theoretically zero to the bottom where the force is maximum. The calculated force of action is one third of the bottom. Thus, the upper two-thirds of the height collectively have the same force as the lower third.

Total gravity force

$$
G=h \cdot a \cdot b \cdot \rho \cdot g=0,4 \mathrm{~m} \cdot 0,5 \mathrm{~m} \cdot 0,5 \mathrm{~m} \cdot 3500 \mathrm{~kg} / \mathrm{m}^{3} \cdot 9,81 \mathrm{~m} / \mathrm{s}^{2}=3434 \mathrm{~N}
$$

\subsection{Economic Evaluation}

The aim of the optimization was to reduce the manufacturing costs of moulds for vibrocasted refractory materials. As an example, there is a comparison of the cost of manufacturing a rectangular mould by using standard wood technology, based on the 
original design, and new manufacturing technology from new perspective materials, based on the new design. The comparison is shown in the following Table 2.

Table 2. Comparison of the Costs of the Original Construction and New Solution of Moulds

\begin{tabular}{|l|c|c|}
\hline \multicolumn{1}{|c|}{ Cost items } & Original construction & New construction \\
\hline Design of mould & $22 €$ & $22 €$ \\
\hline Material & $385 €$ & $77 €$ \\
\hline Production & $151 €$ & $151 €$ \\
\hline Construction & $36 €$ & $32 €$ \\
\hline Total & $\mathbf{5 9 3} €$ & $\mathbf{2 8 2} €$ \\
\hline
\end{tabular}

\section{Conclusions}

This paper deals with the optimization of the production process of vibrocasted refractory products. At the beginning there is an analysis of the current state of the brick production and the mould itself. Subsequently, on the basis of the analysis of vibrocasted products portfolio, the criteria for selecting the appropriate representative are selected, taking into account other circumstances, in particular the production technology.

The aim of the last part of the paper is to describe the production optimization of vibrocasted refractory materials through designing the new mould type. Wooden moulds, which are currently used, are costly and timely to produce and require skilled workers. In this part of the paper, new type of mould is described. It consists of two separate groups of parts - inner mould and outer mould (frame).

By the combination of construction and material design, the new mould was designed. It will cut cost and time of production of vibrocasted materials and will simultaneously ensure top quality of the vibrocasted products. At the end of last chapter optimization criteria are described as well as economic evaluation based on the comparison of the original and the new construction.

This work was supported by the governmental funding of Ministry of Industry and Trade, Czech Republic, program TRIO - project number FV10057.

\section{References}

1. J. Shanmugasundaram, G. Annamalai, B. Venkateswarlu, Casting of concrete pipes by vibro-vacuum technique. Indian Concrete Journal, 62, 7 (1988)

2. Yu.E. Pivinskii, V.N. Nikitin, T.M. Khranovskaya, Vibro-cast periclase refractories of a grainy structure and some of their properties, 7, 437-444 (1986)

3. de Sá, S. França, J. L. Ferreira, A. S. Matos, R. Macedo, A.M. Ramos, A new insight into polyurethane foam deterioration - the use of raman microscopy for the evaluation of long-term storage conditions. Journal of Raman Spectroscopy, 47, 12 (2016)

4. L. Beránek, J. Kyncl, A. Herman, P. Novák, T. Kellner, M. Kyncl, J. Kyncl, M. Vostrovský, et al., Forma pro odléváni žárovzdorných vibrolitých materiálů. Czech Republic. Utility Model CZ 31719 (2018) 